\title{
laborhifórico
}

ISSN 2359-6910

https://revistas.ufrj.br/index.php/lh/

RESENHAS

Recebido em 8 de setembro de 2019

Aprovado em 1 de novembro de 2019

\section{MENDES, M. G.; AMBROSILI, S. S. Crítica textual: volume 1. Rio de Janeiro: Fundação CECIERJ, 2015, 198 p. ISBN: 978-85-458-0002-6}

DOI: https://doi.org/10.24206/lh.v5i2.31061

Marcelo Módolo

Mestre (1998) e doutor (2004) em Filologia e Língua Portuguesa pela Universidade de São Paulo. Cumpriu estágio de pós-doutorado (2006) em Linguística Histórica e Semântica Cognitiva no Instituto de Estudos da Linguagem da Universidade Estadual de Campinas. Atualmente é professor de Filologia e Língua Portuguesa no Departamento de Letras Clássicas e Vernáculas da Faculdade de Filosofia, Letras e Ciências Humanas da Universidade de São Paulo.

E-mail: modolo@usp.br ORCID: https://orcid.org/0000-0001-5808-9368

\section{Maria de Fátima Nunes Madeira}

Graduada em Letras com licenciatura em Inglês e Português (1984). Mestranda no Programa de Filologia e Língua Portuguesa do Departamento de Letras Clássicas e Vernáculas da Faculdade de Filosofia, Letras e Ciências Humanas da Universidade de São Paulo. Seus estudos estão relacionados à Filologia, Paleografia e História da Língua Portuguesa. 


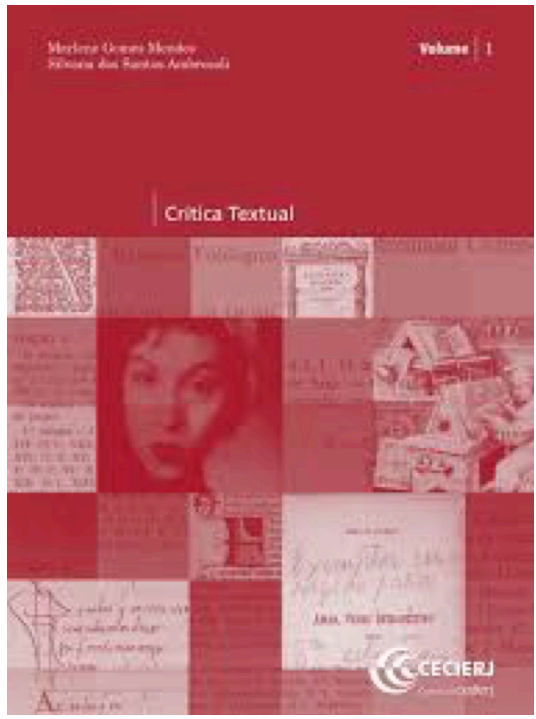

Crítica textual: volume 1, disponível, em formato .pdf, no endereço eletrônico https://bit.ly/34csVGe, foi escrito pelas professoras Marlene C. Gomes Mendes, coordenadora e docente, e Silvana dos Santos Ambrosoli, tutora a distância, para os alunos que cumprem a disciplina Crítica Textual, ministrada no quinto semestre do curso de Licenciatura de Letras a distância da Universidade Federal Fluminense. Trata-se de material que acompanha as dez aulas que compõem a disciplina e vem estruturado, por isso mesmo, em dez pontos.

A consulta ao material é aberta na Internet, agilizando sua utilização por todos os potenciais interessados, em busca de noções elementares sobre a ciência da curadoria de um texto, mas principalmente de confiabilidade, dado o enquadramento institucional da obra em tela. O Consórcio CEDERJ - Centro de Educação a Distância do Estado do Rio de Janeiro, projeto de graduação a distância da fundação CECIERJ - Centro de Ciências e Educação Superior a Distância do Estado do Rio de Janeiro, reúne universidades e instituições de ensino superior públicas, como a Universidade Federal Fluminense, com o objetivo de levar educação superior pública, gratuita e de qualidade para todo o Estado do Rio de Janeiro, por meio de cursos na modalidade EaD (Educação a Distância). A fundação e o consórcio são as instituições responsáveis pela publicação do referido material didático.

Uma avaliação do material levanta, primeiramente, um questionamento acerca de sua adequação pedagógica. Afinal, que características deve ter um bom material didático, específico para cursos de graduação na modalidade de $\mathrm{EaD}$ ? Os especialistas dirão que "tanto o conteúdo quanto o formato devem estar em consonância com os princípios epistemológicos, metodológicos e políticos do projeto pedagógico do curso" (MEC, 2007). Já os alunos, ou ao menos parte significativa deles, buscarão linguagem clara e objetiva, que os aproxime - mesmo à distância - do professor, além de páginas com diagramação "leve", imagens, títulos sugestivos e, claro, mídias digitais.

Quanto a esse primeiro ponto, a avaliação é decididamente positiva. Afinal, de um lado, o material didático atende aos requisitos propostos pelo MEC como referencial de qualidade para as instituições que ofereçam cursos na modalidade EaD: o conteúdo é dividido em aulas, apresentadas por meio de pequenos textos, resumos, comentários, sugestões de leitura e recomendações de uso de outras mídias. As atividades, a seu turno, são elaboradas de maneira diversificada para que o aluno compreenda, reflita, analise, pesquise e aprofunde seus conhecimentos. 
Sob a perspectiva do aluno, pode-se dizer também que os possíveis anseios se encontram devidamente contemplados, já que o material se vale dos mais diversos recursos para facilitar a comunicação: boxes chamam a atenção do leitor para conceitos, explicações ou mensagens das autoras; por meio do recurso visual dos fios, organiza-se o espaço de leitura na página; tabelas facilitam a visualização de dados, como, por exemplo, as transformações sofridas pelos textos em diferentes edições; figuras com legendas ilustram bibliotecas, tipos de suporte de escrita, manuscritos, textos impressos, capas de livros, páginas de exemplares anotadas pelos próprios autores, etc. Além disso, sete aulas apresentam ao menos um recurso tecnológico com link direcionando o aluno para uma imagem, um site ou um vídeo na Internet.

O direcionamento do texto em segunda pessoa ao leitor, amenizando, dentro do possível, a distância física que existe entre professor e aluno, mais os recursos gráficos e audiovisuais, dão ao material o cariz de uma cartilha, no sentido mais didático, qualificado, funcional e receptivo que esse termo possa expressar, perfeitamente compatível com a proposta do CEDERJ de suprir a operacionalização da $\mathrm{EaD}$ com uma "aprendizagem por meio de material atraente em linguagem adequada”. É assim que as aulas sempre começam com um diálogo engajador, relembrando tópicos anteriormente discutidos e incentivando o aluno a construir seu próprio conhecimento. Você já pensou que, ao ter em mãos um poema de Manuel Bandeira, por exemplo, o texto pode não ser o mesmo que ele escreveu? A partir de perguntas como essa, as professoras-autoras combinam várias unidades de conteúdo em pequenas quantidades, favorecendo o processo de memorização e de aprendizagem, ao intercalar textos, imagens e atividades.

Vejamos mais amiúde a forma pela qual as aulas estão organizadas.

As dez aulas são apresentadas em formato padronizado, porém dinâmico, próprio de material escrito para ensino a distância, com a seguinte configuração básica: número e título da aula; meta da aula; objetivos para o aluno; introdução; desenvolvimento do assunto, com subtítulos atraentes, figuras e boxes; atividades correspondentes a cada um dos objetivos, com respostas comentadas; conclusão; atividade final, com respostas comentadas; resumo; informações sobre a aula seguinte. Os alunos podem até prever o formato genérico das aulas, mas, naturalmente, os recursos gráficos variam de acordo com as exigências de cada capítulo. Por exemplo, nos capítulos iniciais, a presença dos boxes é mais notável, já que as primeiras aulas exigem a conceituação de vários termos ainda desconhecidos, como, por exemplo: autenticidade, fidedignidade, copista, códice, acervo, iluminura, etc.

Com a definição da meta e dos objetivos logo no início da aula, o aluno pode se concentrar no conteúdo que será apresentado, e se preparar para realizar as atividades sugeridas. As respostas comentadas, mais que simples mecanismos para verificação da resposta correta, são instrumentos que ajudam a desenvolver a segurança, a organização e a autonomia do aluno. A conclusão orienta o aluno a conferir se a meta sugerida para a aula realmente foi atingida. E o resumo possibilita ao aluno avaliar 
o próprio processo de aprendizagem, verificando se efetivamente foram adquiridas as habilidades necessárias para realizar as propostas apontadas na seção objetivos. O tópico informação sobre a próxima aula, presente ao final de cada capítulo, cumpre o significativo papel de integrar as unidades, convidando o aluno para a próxima etapa do aprendizado, e acenando com um simpático "até lá!".

Identificadas por suas fontes, as imagens exibidas em cada aula são numeradas como figuras, algumas estáticas, apenas para visualização na página onde estão inseridas, outras com legendas em forma de hipertextos, que remetem, pela Internet, ao site de origem, onde as imagens podem ser observadas com maior nitidez ou, se for o caso, com as cores originais, já que no texto se apresentam em tonalidade acinzentada. Consultadas no dia 16/11/2019, algumas dessas figuras haviam perdido seus links com as fontes.

Os vídeos são identificados com um ícone em forma de máquina filmadora. Entretanto, quatro dos dez links assinalados com esse ícone levam o leitor não a imagens em movimento, em formato de vídeo, mas sim a uma página de site de jornal, de revista, ou de bibliotecas. Além disso, dentre os seis links que, acionados, levariam o leitor para os vídeos na Internet, dois estão inativos, embaraço que, somando-se ao das figuras que também perderam seus links, evidencia uma recente e global necessidade que se impõe aos materiais relacionados à cultura digital, ou seja, a constante verificação e atualização dos links nos sites onde ficam hospedados.

$\mathrm{O}$ item atividade vem destacado dentro de um box e assinalado por um ícone, sendo facilmente identificado no texto. Quando a aula atinge conteúdo suficiente para uma revisão, o aluno é convocado a realizar as atividades correspondentes a determinado(s) objetivo(s) da aula. Embora haja espaço com linhas para se completar as atividades, como o formato PDF não permite edição tão fácil como outras modalidades textuais, ao aluno restam algumas opções: imprimir as atividades e completá-las na folha impressa; escrever as respostas em papel avulso ou caderno; ou digitar em processador de texto. Provavelmente, o aluno deve ser orientado a realizar as atividades da maneira como preferir e somente depois disso conferir as respostas, já que na educação a distância o aluno é incentivado a estudar e pesquisar de modo independente.

Com apresentação gráfica diferenciada das demais atividades, a Atividade final de cada aula lembra uma prova. Somente na aula 9 , faltaram as linhas para resposta a essa atividade.

Um segundo ponto na avaliação do material, em que também a conclusão é positiva, diz com a qualidade propriamente epistemológica da obra, vale dizer, seu adequado processamento do patrimônio acumulado pela disciplina.

Note-se, de partida, que o título do caderno - Crítica textual - alude à antiga e recorrente discussão a respeito dos conceitos de Filologia, Ecdótica e Crítica textual, todos com pretensão a designar de modo abrangente o campo disciplinar. As autoras enfrentam o tema logo nos dois 
primeiros capítulos do material. A predileção das faculdades de Letras de diferentes universidades pelas designações de Crítica textual (por exemplo, a Universidade Federal Fluminense e a Universidade de Lisboa) ou de Filologia (por exemplo, a Universidade de São Paulo), revela, por certo, a falta de consenso sobre a designação do campo, mas, felizmente, a escolha não interfere na qualidade das práticas filológicas, acadêmicas, nem didáticas, limitando-se apenas a uma questão terminológica. ${ }^{1}$

Afinal, conforme se depreende do sumário, os títulos das aulas coincidem com o roteiro geral dos principais manuais brasileiros de crítica textual, que são ademais citados como referências bibliográficas no material didático, tais como o de Azevedo Filho (1987), de Spina (1994) e de Cambraia (2005). São eles: "Falso ou verdadeiro? Introdução à Crítica Textual: sua origem, conceito e objeto" (aula 1); "Filologia, Ecdótica, Textologia. Transdiciplinaridade: ciência auxiliares” (aula 2); "Crítica textual antiga e moderna. Manuscritos: apógrafos, idiógrafos, apócrifos e autógrafos. Manuscritos do Mar Morto. Textos impressos" (aula 3); "Principais tipos de edição: paleográfica, diplomática, fac-similar, crítica, genética e crítico-genética. Transcrição diplomática e transcrição crítica" (aula 4); "A autenticidade e fidedignidade dos textos. Textos literários. Problemas relativos à autoria de textos" (aula 5); "A crítica textual moderna: Karl Lachmann e sua contribuição para a renovação. Outros teóricos. Normas para a edição de textos" (aula 6); "Tarefas da crítica textual. Distinção entre edição crítica e texto crítico. Principais problemas na transcrição crítica do texto: grafia e pontuação. Estabelecimento de um texto crítico" (aula 7); "Preparação e partes da edição crítica" (aula 8); "Prática de registro de variantes: poesia" (aula 9); "Prática de registro de variantes: prosa” (aula 10).

Ora, se o livro tem concepção pedagógica adequada e, ao mesmo tempo, acertada compreensão do panorama disciplinar, é interessante verificar como a primeira funciona como veículo da segunda, favorecendo a exposição e a transmissão de conteúdos complexos, isto é, facilitando o aprendizado sem simplificar ou aligeirar a matéria.

"Mas que disciplina é essa? Como tudo começou?" Essas dúvidas, que emprestam sua voz ao aluno, são respondidas explicando-se o conceito e a história da crítica textual. O subtítulo "Juntos e misturados”, alusão a título de filme americano e a um popular mote de programa brasileiro de televisão, chama para o debate sobre a nomenclatura e o campo de atuação dos termos Filologia, Ecdótica e Textologia. E o subtítulo "Auxílios luxuosos”, plural da expressão presente na canção "Juventude transviada", de Luiz Melodia, entoa a relação de transdisciplinaridade entre as ciências que interagem no trabalho de recuperação dos manuscritos, como a epigrafia, a paleografia, a codicologia, a diplomática e a linguística. A nomenclatura de tópicos é, assim, chamariz para a atenção, forma de propiciação ao aprendizado, continente que emoldura o conteúdo, sem descaracterizá-lo.

\footnotetext{
${ }^{1}$ Sobre a falta de uniformização da terminologia filológica, ver Madeira (2020, PRELO).
} 
No segundo capítulo, no decorrer de discussão séria em torno do conceito de ecdótica, ao citar o uso que o filólogo Antônio Houaiss faz desse termo em seus Elementos de bibliologia, o leitor é remetido a um vídeo de 1990, na plataforma YouTube, em que se vê o filólogo no programa Roda Viva, da TV Cultura, respondendo a uma pergunta sobre o acordo ortográfico que estava por se estabelecer entre países falantes de língua portuguesa. Uma experiência tecnológica inestimável, porque proporciona o encontro do professor, falecido em 1999, com várias gerações. Forma notável de lidar com a cultura da Internet, imbricada com a multiplicidade de abas abertas no computador. Potencial disruptivo da atenção que, perspicazmente, é utilizado para envolver o aluno no aprendizado pelas formas de funcionamento do que se pode legitimamente supor ser sua forma de interação com a tecnologia.

$\mathrm{Na}$ terceira aula, são apresentados os tipos de textos: manuscritos e impressos. Exemplos de textos apógrafos, apócrifos, autógrafos e idiógrafos são mostrados em imagens no próprio texto. Vídeos no YouTube ilustram os manuscritos apócrifos do Mar Morto e a impressão de um livro em linotipo. O recurso é acertadamente reproduzido ainda outras vezes, como, a título de ilustração, na sétima aula, em que as autoras indicam o site da Biblioteca Nacional, onde boa parte das obras raras de Clarice, digitalizadas, pode ser pesquisada; e um vídeo, no YouTube, de 1977, em três partes, com a última entrevista em vida dada pela autora. E esse é mais um link que merece todos os cuidados possíveis para continuar ativo no texto. Assim, imagina-se, vão se multiplicando as abas a compor a experiência de aprendizado do aluno, e o que seria potencial de desconcentração vai se tornando ambiente de colonização do aluno dentro do mundo da crítica textual (ou da filologia....).

Não que o mundo digital vire um mundo à parte na complexa experiência pedagógica alavancada pelo manual em comento. Antes, esse mundo aponta para o mundo dos objetos sobre os quais a crítica textual ainda majoritariamente consagra seus esforços. Assim, na sexta aula, dedicada a uma apresentação sumária de Karl Lachmann - o filólogo alemão cujos métodos científicos pautaramse por eliminar a subjetividade do editor na reconstituição do texto original perdido, a partir de processos e fases mecânicas, escrupulosamente efetuadas -, as autoras exemplificam com edições de texto e arrematam com uma oportuna sugestão: "Se você tiver curiosidade de ver primeiras edições ou obras raras da nossa e de outras literaturas, acesse o site da Brasiliana da Universidade de São Paulo, onde se encontra a biblioteca de José Mindlin, um dos maiores bibliófilos do Brasil”.

Não há, assim, ilusão de autossuficiência do mundo digital sabiamente explorado na obra. Por exemplo, na aula 7 , as tarefas do crítico textual são lidas diretamente no artigo do professor Maximiano de Carvalho e Silva, "Crítica Textual: conceito, objeto, finalidade" (1994). Sobre a mais importante das tarefas do crítico textual - a recuperação do patrimônio cultural escrito de determinada cultura - as autoras se reportam ao manual de Cambraia (2005) para citar uma conhecida trapalhada 
tipográfica que exemplifica apenas uma dentre as prováveis consequências indesejáveis de uma edição mal preparada utilizada como fonte para estudos e pesquisas.

"Ao pegar um livro para ler ou estudar, você se preocupa com o tipo de edição que tem em mãos?" Com essa pergunta, as autoras unem os temas das aulas 3, 4 e 5, levando o leitor à reflexão sobre "a indiscutível necessidade de profissionais competentes, com boa formação, conhecedores dos critérios que norteiam a preparação de edições fidedignas, para que as futuras gerações tenham acesso a bons textos”. O livro não se virtualiza nem desaparece. A injunção das autoras é mesmo por uma experiência que não apenas ultrapasse o ambiente virtual em busca da materialidade objetal do mundo da crítica textual, mas ainda se construa em estreita intersubjetividade: "Vamos à prática?", convidam as autoras ao introduzir as duas últimas aulas e propor a seguinte dinâmica de trabalho:

A colação deve ser feita, preferencialmente, por duas pessoas: enquanto uma lê o texto de base, a outra vai corrigindo os erros e fazendo o registro das variantes. A leitura tem que ser lenta e pausada, marcando a pontuação e qualquer forma ou grafia que possa parecer estranha ao preparador do texto.

Portanto, impõe-se a conclusão de que o êxito pedagógico e o êxito crítico da obra estão em estreita dependência, notadamente pela engenhosidade com que souberam as autoras se valer do meio digital como experiência propiciatória à descoberta do mundo da crítica textual. Uma única ressalva que levantaríamos tem que ver com a abordagem da transcrição. As autoras definem a transcrição como "processo de produção de novo testemunho de um texto, levando em conta suas características". E denominam as normas básicas utilizadas para determinado tipo de edição como tipos de transcrição. A transcrição diplomática, por exemplo, é definida rigidamente como "a transcrição fiel de um texto, na qual devem ser mantidos todos os caracteres, tais como grafia das palavras, pontuação, abreviaturas". Já na transcrição crítica, segundo as autoras, "devem ser corrigidos os erros cometidos por terceiros, aqueles a que chamamos óbvios, como troca de letras, acentuação indevida. A grafia também deve ser atualizada, de acordo com as normas vigentes, respeitando-se, no entanto, a pontuação do autor”.

Segundo Cambraia (2005), porém, a transcrição é apenas um dos procedimentos básicos para a realização de uma edição. E, para realizar qualquer uma das possíveis formas de transcrição, sempre é necessário determinar como serão transcritos os elementos de cada modelo: caracteres alfabéticos, abreviaturas, separação vocabular, diacríticos, pontuação, paragrafação, sinais especiais. Além disso, ensina o professor que essas normas devem ser definidas para cada edição. No caso da edição crítica, por exemplo, é possível adotar uma transcrição mais conservadora ou mais uniformizadora, dependendo do público-alvo. Pensamos que uma segunda edição dessa exitosa obra pudesse 
aprofundar alguns desses elementos, como forma de conferir maior densidade e clareza à atividade fundamental da transcrição de textos.

O livro termina com o seguinte aceno: "Em nossa próxima aula, vamos fazer o caminho inverso, ou seja, através do registro das variantes, reconstituiremos textos de mais de uma edição ou publicação. Até lá!"

Esse convite, a expectativa que o livro desperta nos leitores por um novo volume e a frustração de não o encontrar na Internet evidenciam o êxito das professoras-autoras, que atingiram os objetivos propostos para um curso de crítica textual - e a distância - com primazia. Da mesma forma, podemos constatar o atendimento, pelo Consórcio CEDERJ e pela fundação CECIERJ, a todas as demandas da engenharia pedagógica exigidas para a publicação de materiais didáticos destinados à educação a distância, contribuição que leva a outro debate da atualidade, a necessidade e a eficácia dos cursos a distância.

O leitor mais atencioso deve ter percebido os diferentes termos atribuídos, nesta resenha, ao material didático Crítica textual-volume 1: publicação, material, material didático, material de estudo, cartilha, caderno, texto, livro. E-book e guia de estudo também poderiam ter sido empregados. Mas nenhum desses termos define tão bem o material quanto a palavra utilizada pelas próprias professorasautoras: AULA. Enfim, a leitura de Crítica textual revela-se imperativa para os que se iniciam nos estudos filológicos e desejam servir-se de um texto propedêutico claro e objetivo, que apresente conceitos fundamentais para pavimentar a longa estrada que se apresenta à frente na formação acadêmica. É, sem dúvida, um livro que se impõe nos primeiros momentos do estudo filológico e que se revela igualmente útil mesmo para os que não fazem da filologia seu mister, mas que se interessam por questões de filologia e desejam enriquecer seu conhecimento sobre o trabalho de edição.

\section{Referências bibliográficas}

AZEVEDO FILHO, L. A. Iniciação em crítica textual. Rio de Janeiro: Presença Edições: São Paulo: Editora da Universidade de São Paulo; 1987.

BRASIL. Ministério da Educação. Referenciais de qualidade para EaD. 2007. Disponível em: https://bit.ly/2RJZEjp

CAMBRAIA, C. N. Introdução à crítica textual. São Paulo: Martins Fontes; 2005.

Curso de licenciatura de Letras a distância- UFF. Disponível em: https://bit.ly/38tZKBS 
MADEIRA, M. F. N. Unificação de termos na filologia: diálogo transdisciplinar e qualificação dos trabalhos. Estudos linguísticos do GEL; 2020 (PRELO)

SILVA, M. de C. e. Crítica Textual: conceito, objeto, finalidade. Confluência, Rio de Janeiro, n. 7, p. 57-63, 1. sem. 1994.

SPINA, S. Introdução à edótica: crítica textual. $2^{\mathrm{a}}$. ed. Revista e atualizada. São Paulo: Ars Poética: Editora da Universidade de São Paulo; 1994 